\title{
Strangers No More: Collaborative Inquiry Through Narrative as Teacher Reflective Practice
}

\author{
Elia Gindin, Meaghan van Steenbergen, and Douglas L. Gleddie
}

\begin{abstract}
Two teachers and a professor engaged in collaborative inquiry through narrative as a form of reflective practice, pedagogical growth, and practitioner research. Using a Deweyan lens and elements of narrative inquiry, we consider our stories of teaching through a supportive, growth-based sharing process. Viewing pedagogical experiences through this lens enabled us to enter each other's worlds and engage in reflection-together. Our work speaks to the situations that arise when expectations conflict with reality. The process of reflecting and re-reflecting led us to the conclusion that engagement in this fashion is a valuable reflexive method for teacher professional growth.

Looking forward to more discussion - putting these stories to paper is so therapeutic...it is seriously so difficult to stop writing when you are reflecting and connecting once you get going... (Elia)

Working with you and Elia has taken me down a path that I didn't expect my Master's experience to ever take, and I know I'm speaking for both of us when I say that this path has been both career-changing and incredibly educational. (Meaghan)

It was so good to finally meet you both, have a good long chat and continue working together! I also feel quite blessed and am excited to keep this project going. Re-reading your monthly posts was so inspiring - thanks to you both for all of your dedication and commitment to the project. (Doug)
\end{abstract}

Our journey began as two graduate students and a professor together in an online course on reflective practice. As working professionals, we shared an acknowledgment that understanding, and even growth, is somewhat limited when one participates in individual reflection. We felt affected by past professional stories and recognized that participation in narrative-based research of a collaborative nature could have a positive impact on our future professional experiences. Our contexts, experiences, and lives are different, which we believed would have a positive impact on discussion and analysis. This paper emerged out of a final project where Elia and Meaghan shared key teaching moments with each other electronically and engaged in a form of inquiry (reading, reflecting, responding, and repeating) through narrative. Doug was so moved and impressed by their project that he asked if they might be willing to keep it going, and add him to the process. We put a formal plan in place and called it collaborative inquiry through narrative. ${ }^{1}$ Elia and Meaghan would share one story a month (through Google Docs) for a span of four months, with each of us reflecting, responding, and re-reflecting in the document. The title of the paper comes from the fact that although we connected online and only actually met in person once (after working together for eight months), our reflective journey continues now as colleagues, teachers, and friends. 


\section{Reflective Practice and Narratives in Education}

"Teachers cannot separate their personal identities from their professional ones" (Estola, 2003, p. 181).

Narrative inquiry, as a methodology, uses collected stories as the means to understand experience and is "...increasingly used in studies of education experience [because] the main claim for the use of narrative in educational research is that humans are storytelling organisms who, individually and socially, lead storied lives" (Clandinin \& Connelly, 2000, p. 3). Schaefer and Clandinin (2011) explored the connection between teachers' visions of what they expected teaching to be, and the experiences that presented themselves. In the middle ground, we find our stories and, according to Dewey (1938), room for growth. As practitioners interested in exploring our own personal and professional landscapes, we found ourselves drawn to narrative-based research.

Inquiry through narrative separates itself from "typical story sharing" and transcends peer relationships. It involves a deeper reflection and level of inquiry into the narratives. Therefore, the aim of our paper is to share how we used collaborative inquiry through narrative as a method to reflect on personal experiences in our day-to-day lives as practitioners. We hope to encourage teachers "to resist the establishment of classroom control [by instead becoming] reflective practitioner(s), continuously engaging in critical reflection, consequently remaining fluid in the dynamic environment of the classroom" (Larrivee, 2000, p. 306). We also hope to emphasize the transformational nature of using elements of the narrative inquiry process as practitioner reflection. In our context, reflection became the lens through which we, as a collective, began to examine the intersections of our personal and professional experiences.

Reflection is not an end in itself but a tool or vehicle used in the transformation of raw experience into meaning-filled theory that is grounded in experience, informed by existing theory, and serves the larger purpose of the moral growth of the individual and society. (Rodgers, 2002, p. 863)

Rodgers' (2002) ideas of reflective practice are compounded with the notion that teachers must learn from these stories amidst the critical examination of their practice: by seeking the advice of others, drawing on educational research to deepen their knowledge, sharpen their judgment, and adapt their teaching to new findings and ideas.

Reflection in practice allows educators to improve by reflecting deeply on their challenges, successes/errors, and accomplishments, while creating stories based on everyday experiences. The stories that we shared with each other, and following responses and re-reflections, began to change and shape the way we were viewing our practice. The stories we might have at first been reluctant to share, were quickly becoming integral pieces to our professional development journeys. The new perspectives through which we were viewing the challenging experiences in our classrooms allowed us to begin to understand the relationship between the authentic experiences that we lived each day, with that of inquiry and the stories we were ready to share. By the end of the first reflective experiences, we were becoming improved inquirers due to the in-depth explorations of our teaching experiences and the desire to assist each other through continuous reflection. As Patton and colleagues (2013) state, 
we engaged in, "Carefully orchestrated [professional development] with purposeful steps used by facilitators to aid teachers in becoming independent and life-long learners" (p. 456). Therefore, one might call our process of collaborative inquiry through narrative a type of community of practice (Parker et al., 2012). Our reflective community acts as a learning group that promotes a supportive and safe environment for all (Parker et al., 2012) as we inquire together to shift our practice.

The way we have structured our reflective practice has truly enabled us to "...better understand why we are who we are; why we do what we do; [and] why we believe what we believe" (Gleddie \& Schaefer, 2014 , p. 3). Even further, we used inquiry through narrative as a methodology to share and analyze our thoughts and everyday encounters in our schools, since expressing our experiences as stories allows for a pragmatic ontology leading to action. The stories of our experiences are the foundation of our inquiry, and, in turn, the inquiry itself has provided us with the necessary process to gain a deeper understanding of the experiences in our classrooms and schools.

Although our work is not "true" narrative inquiry, we accessed aspects of the methodology as a foundation on which to base our experimental work in reflective practice. For example, we used Clandinin and Connelly's (2000) three-dimensional narrative space as a way to structure our reflective interactions (see next page). As reflective practice is deeply entrenched in Dewey's experiential theory (1938), it implies that pedagogical learning is most effective when teachers are able to live through personal experiences and reflect back on them as the basis for professional learning. Therefore, we ground our conceptualization of reflection with Dewey (1964), who explained that reflective practice "...is important not only as a tool for teaching, but also as an aim of education, since it enables us to know what we are about when we act." (p. 211). As such, reflection as a method of questioning is extremely important in teaching, and provides the basis for the work of this paper. Dewey (1964) defined what reflective practice was for a teacher in such a way that inspired and promoted a movement of self-awareness and the critical evolution of professional development through story. Teachers today are coming to realize that in order to better understand themselves in the classroom, they need to see their "...knowledge in terms of narrative life stories" (Clandinin \& Huber, 2002, p. 161).

\section{Methods}

The purpose of our reflective journey was to grow as professional educators. Schaefer and Clandinin (2011) describe what we have done as a "bumping"' (p. 283) of stories. They argued that teachers' styles bump against what is expected of them. Our experiences shape our original expectations of what the profession will bring, and as our careers progress, we monitor and adjust to new circumstances (Farrell, 2016). In more traditional narrative inquiry settings, authors often share a context as colleagues in the same school or as part of a professional cohort. In our case, we came together first as strangersunited by our common experience of an online course on reflective practice. Meaghan and Elia taught different grades and worked for different school boards. Each had unique experiences with students, parents, administration, and professional development. Both had prior experiences outside the city, but in vastly different areas of the world. Doug taught for 14 years, but has been a professor for the past 11 . 
The final class assignment required the development of an open-ended "reflective practice project," which Meaghan and Elia ended up collaborating on. When we considered our stories, we were already familiar with our own associated thoughts and emotions. We wanted to explore the impact of those stories through a wider lens, which we hoped would come from working alongside one another. Through monitoring the development of the project and assessing the final product, Doug was drawn further into Meaghan and Elia's worlds through their stories, reflections, and analysis. As a result, we agreed to continue the project (with Doug on board as an additional "reflector" and "connector") through another term as an independent study, and planned to share our collaborative process and learning journey.

Following Greene's (1995) suggestion that, "One must see from the point of view of the participant in the midst of what is happening" (p. 10), Meaghan and Elia each chose and shared a story from their teaching experiences. We then read the shared stories, looking to understand the writer's feelings and context, but also bringing our own experiences to the table. The final step was a collaborative reflection, a "back-and-forth" examining the experience through shared reflections. Each month, we shared a different story and embarked on a new reflective process. A relationship of friendship and trust was built and strengthened with every new story. In a profession that usually only allows the individual teacher to consider events in the classroom, the invitation to read each other's stories and reflections opened the door for support and mutual mentorship.

We structured our reflections around Clandinin and Connelly's (2000) three dimensions of narrative inquiry space: the personal and social (interaction) along one dimension; past, present, and future (temporal) along a second dimension; and place (situation) along a third dimension. They define this process by explaining that,

Using this set of terms, any particular inquiry [can be] defined by this three-dimensional space: studies have temporal dimensions and address temporal matters: they focus on the personal and the social in a balance appropriate to the inquiry: and they occur in specific places or sequences of places. (p. 54)

Personal growth develops from reflection of the nature of relationships with others and in mind with our personal expectations and stories. This marks the personal/social dimension, and our stories in this paper will demonstrate the natural connection to the place dimension. The temporal dimension describes a continuity from past to present to future. This dimension is vital to the reflective process as it is where we engaged with the concept of understanding and growth, and prepared us for the next cycle of reflection.

We cannot possibly share all the stories, reflections, and analysis here. Therefore, we chose a story fragment from both Meaghan and Elia (along with a snapshot of the accompanying reflective process/analysis we went through) as exemplars to illustrate our journey. The future is marked by growth as we draw connections between past and current events, the pieces coming together to form our own unique puzzles (Gleddie \& Schaefer, 2014). 
Strangers No More: Collaborative Inquiry Through Narrative as Teacher Reflective Practice

\section{Elia's Story}

Every day from 12:45-1:00 pm, all students in my school have 15 minutes of uninterrupted silent reading time to read quietly for pleasure. In the first week of school, much to my surprise, I actually heard a student (male), who didn't bring a book, say to another boy, who was quietly reading, that "reading was for girls!" I absolutely cringed. I know it was only the first days of school, but what was I doing wrong? Did I not foster an inclusive classroom in these early days? Were the kids not connecting with me (or each other)? My single job on the first days of the new school year is to promote an environment of acceptance and friendship amongst my students, and I was obviously failing.

The boy, now in tears, left the class. When I approached him, he said to me, "Teacher, you don't know me yet, but reading is all I got. I am not good in the gym like most boys. Reading is my thing!" He was right-I didn't know him well at all yet and I felt defeated, on this, the very first days of the school year!

I brought the issue of reading and boys to the staff room and it was especially intriguing listening to my colleagues discuss the perils of trying to get boys to enjoy reading; some believed you needed to "let boys be boys" and have them read for pleasure without pressure, while others suggested to not have them read at all because "they'd eventually find something to read, or not." But as an educator, I could not sit idle and allow kids who can read choose not to when those who probably cannot read, only wish that they could.

This situation left me with more questions than answers, especially as a non-PE teacher with a student who believed they were being judged for not being athletic, and how can I help promote a healthy definition of masculinity in my classroom for those boys who want to excel academically, but do not think they can simultaneously succeed in PE class.

As the year progressed, I realized that I had to cultivate an open-minded classroom where the kids who liked to read would be valued as much as the kids who were athletic, just as my teachers did for me when I was in junior high where there should be no judgments on abilities or disabilities, likes or dislikes. I remember that I too was once in a similar situation as the awkward teenager who wasn't as comfortable in the gym as he was in the Language Arts classroom, and although I persevered, I was constantly made fun of for doing the things that "girls liked."

That kid who cried on the first day of school now commands quite the audience as he describes the kinds of books he reads weekly_ other students are in awe of how he reads two or more books a week! Furthermore, I was astonished that the same kid who proclaimed that he couldn't do sports, was playing badminton in gym class and throwing a football at recess. Perhaps I wasn't failing as his teacher after all?

\section{Meaghan's Response}

This story demonstrates how the three dimensions are relevant when we consider the narratives of teachers. It seems more difficult, however, to define these when we are speaking about teenagers. In the first days of any school year, a teacher has a solid foundation for what their place is. They have spent time organizing their classroom, meeting new colleagues, creating lesson plans and seating charts. Yet, that same place is not defined at all for our students. They walk into the room anxious to be told where to sit and what to do. They define their new place by what it was to them last year, yet their new teacher will soon influence their present interpretations. For the boys in the story, both had preconceived ideas about Elia's classroom. The reader was comfortable and likely looking forward to his year in Language Arts. The subject area had been a comfortable place before, and he used that past 
Elia Gindin, Meaghan van Steenbergen, and Douglas L. Gleddie

experience to create his expectations for the current year. Unfortunately, it was to the point that he believed that the Language Arts class was the only place he could be comfortable.

For the other boy who teased the reader, the reverse was true. He found comfort in Gym class, and none in Language Arts. Formed by past experience, his discomfort was so intense that he felt like he didn't belong in Elia's class and wouldn't risk trying to fit in. He faced a clash of past expectations and present experiences when he was seated next to a boy who was not only comfortable participating in class, but was actually enjoying it.

The future that these boys have in front of them is not theirs alone, but everyone's who is in Education. The sociality of the associations with various subject matters needs to change. Just as Elia guided the reader on his transformation into being a well-rounded student, it is our obligation to help all students develop confidence and a sense of belonging, no matter which classroom they find themselves in.

\section{Doug's Response}

This one hit close to home for me. As a male who likes BOTH physical education and reading I struggle to understand how we are still fighting these gender stereotypes in 2016! I was immediately reminded of a "place" in my house growing up where the reading box went. Every two weeks we went to town to get groceries and also hit up the library - the books would go in the reading box. Invariably, I would end up reading mine and everyone else's over the two weeks. My family never teased me because we were all readers. Elia, you have made your class into that "place" where reading is accepted and encouraged.

Creating places is hard. It takes time. Meaghan makes a great point about the difference between teachers and teenagers when it comes to the place that is a classroom. Elia, you know that you have created a safe and nurturing environment. It takes the students a little longer to buy in and make it theirs too. Socially, it also takes time for students to adapt and adjust to the social norms in your class (reading is NOT masculine or feminine-it is human!). The initial negative interaction gave way to the class culture that was initially created and facilitated by you-then adopted and internalized by the students.

Finally, I am hit by the temporal aspects of your shared story. When Meaghan talks about the future of these boys belonging, in a way, to everyone - she nails it. We can't possibly know all that went on in these kids' pasts. Sometimes as teachers it feels like we barely know their present state... I do know that regardless of what educative or mis-educative (Dewey, 1938) experiences YOUR students have had with reading in the past, in the present, they will be reassured that reading is for boys. And girls. And teachers. And that will have an immeasurable impact on their future.

\section{Meaghan's Story}

When I was 22, I accepted my first teaching job teaching a three-grade split in a rural Canadian town. Nervous, yet excited, I knew the job would be a challenge, but I wasn't prepared for the reception from the community. When I got there, I discovered that it was generally accepted for newcomers to be completely ignored by the adults in the town. Even standing in line to pay for my groceries, I wouldn't be served until there was a line behind me. The kids were different. They filtered their parents' jadedness. The school was our safe spot. Everywhere else I went, I felt uncomfortable. Being a single, young woman didn't help me feel safer. The RCMP detachment in our town was one of the busiest in 
Strangers No More: Collaborative Inquiry Through Narrative as Teacher Reflective Practice

the country, with sexual assault being a common charge, fueled by a level of alcohol and drug abuse I had never seen before in my suburban upbringing.

Sometimes, it infiltrated our classroom. One morning, I was in the middle of teaching when a student's father, Dallas (a pseudonym), walked into my classroom. I could tell that Dallas was inebriated right away and I convinced him that we should talk in the hall. I felt the pain of his child's embarrassment, seeing his father stumbling into his classroom in such a state. Dallas wanted to have an impromptu parent-teacher conference. He was persistent. This man, bulky and outsizing me by at least twice my weight, was well known for getting into trouble with the RCMP. I wasn't about to purposely make him angry. I thought about a professor I had in university, who once said, "Parents will try and march into your classroom to talk to you. Remember that you are a professional. You can't walk into a doctor's office and demand to see the doctor right away, and the same rule applies to schools."

As a naive preservice teacher, I thought that was some really good advice, optimistic that the metaphor had just the right wording to turn any stubborn parent into an understanding one. Now, being in the very situation my professor warned us about, I didn't think that Dallas would be so understanding. Lecturing him for being inconsiderate would not work, and neither would denying him the right to talk about his child. With a classroom of unsupervised teenagers waiting for me, I needed to end this conversation. I forced a smile and championed Dallas for being such a great father who cared so much about his son. When I pointed out that his son wasn't learning anything if I was standing in the hallway, I was able to convince him to come back after school. At least then, I could guarantee that my principal would be close by.

\section{Elia's Response}

When I think about the three-dimensional narrative inquiry space, I am drawn to the temporality of your story and how this experience might have affected your current and future interactions with the parents of your students. We know that when we reflect on events in our professional past, our thinking and how we function pedagogically can philosophically change-the question becomes how that change is regarded and acted upon. After all, "events and people always have a past, present, and a future (and) in narrative inquiry it is important to always try to understand people, places, and events as in process" (Clandinin et al., 2007, p. 24). Therefore, I would be interested in hearing further reflections one day about how this particular experience may be entrenched in your practice; do you think about this incident often? Did you ever contemplate switching professions as a result of this occurrence?

Considering the dimension of place, I immediately thought to myself how uncomfortable you must have felt being in a new and almost foreign setting. The remoteness of the rural Canadian school in which you were based at the start of your teaching career seems daunting and taxing. You were already at a disadvantage being in a completely new geographical space without the support system you would have had at home, so the determination and fortitude you displayed in the situations you endured, absolutely amazed me. However, it did make me wonder if when you were told, "they won't look at you because they think you'll be another teacher gone in a year," if you ever began to regret your decision to move and teach there in the first place? I also think to the specific place of you and Dallas meeting in the hall and if between your professor's past words and the classroom of "unsupervised" students gave you the confidence needed to persevere in this awkward situation you found yourself in, or, were you frightened into finding a quick solution - the families of our students should be part of our educational team, not our adversaries. 
Elia Gindin, Meaghan van Steenbergen, and Douglas L. Gleddie

Personally, what struck me most in this reflection was when you shared about being ostracized by the community. It made me feel isolated, as well as made me question whether or not I'd have the confidence to walk into that classroom every day knowing that. I find that teaching requires a certain amount of self-assurance, and although teachers tend to "give it their all," there are so many pedagogical impediments we face every day, let alone knowing that the teacher, the person who is supposed to lead the class, is already one step behind. Also, even though "Research suggests that parental involvement in the educational system fosters intellectual and emotional growth in children" (Silbergleid, 1998, p.4), if you don't have the support of the parents in the first place, then the relationships with families that teachers are supposed to make, become even more difficult to make. Additionally, since (on average), "Almost a quarter of entering public-school teachers leave teaching within their first three years" (Boyd et al., 2008, p. 1), it is beyond praiseworthy that some teachers are still teaching after all they go through.

\section{Doug's Response}

Courage. That's the word that came to mind first when I read your story. It takes courage to teach somewhere "out of your element"; to think of the child first; to look past behaviour to acknowledge a father. Like Elia, I am intrigued by the dimension of temporality in your story. Your first year of teaching - a tough year anywhere - but even tougher as an outsider in a small rural town. You reflect back to the time of teacher education and recognize, very succinctly, the disconnect you felt in that present time. How much of that first year teacher is in your teaching today? I can only assume that the wisdom you displayed back then has been further tempered by experience and plays a (daily?) role in your interactions with parents today.

Places also have a key role in your narrative. The place of preservice education-a space where professors are safe to say things that fail to match the reality of teaching places - present and future. Your teaching place, where your safety was emotionally and physically threatened. How do those places now manifest themselves in where you are now? Your class, your school-the parents in these places? Do you think of that first year often? I also wonder how long you stayed in that place and how much of it did you take with you when you left?

It is hard being "the other." Interesting that the kids were more accepting than the adults-even though they are the ones impacted (hurt?) the most by those that leave. From a social perspective, I wonder if the parents in that community harden their hearts because they have been taught by experience to not open up to those who will not stay. They harden their hearts because their kids (all kids) can't—it's not in the nature of kids to think too far in the future, but the parents have to. The courage you showed in this situation is one that puts relationships, and the preservation of those relationships, first. You acted out of concern for the child in your class and also for the family. Again, I would guess that this commitment to "people-first" has stayed with you and manifests itself daily in your current teaching role.

\section{Discussion}

The characters from our past stay "...alongside us now as we make pedagogical decisions in our classroom" (Gleddie \& Schaefer, 2014, p. 11). The stories that we chose to share with one another were purposeful because even though these events happened in the past, they resonate with us to this day. As we saw in Elia's story, his role was inspired by events from his adolescence. In Meaghan's story, we saw a beginning teacher struggling to equate her reality with her preservice expectations. Through sharing 
our stories within the three-dimensional narrative space, we acknowledged the importance of temporality within our stories.

From personal reflection, the stories have taught us lessons and guided some of our actions; yet by sharing them with one another, we discovered another level to our pedagogical path. Meaghan was giving voice to her silenced younger self. Elia took action on injustice and guided students on their own journeys. The environments that we found ourselves in demonstrated the sociality aspect. Elia's connections with his students, his desire to guide them on their journey of self-discovery, demonstrate how his relationships with his own peers as a student represent themselves in his classroom. For Meaghan, the desire to present herself as a professional was challenged by the relationships she formed with her students' parents. In both stories, the outcome was guided by our relationships.

Place also acted as a dynamic character in each story. As Casey (1997, as cited in Ellis, 2005) notes, "place is not viewed as having a fixed or single meaning, essence, or structure" (p. 55). For each character in the story, place plays a different role. For Meaghan's students and their families, the small town was home, one that they were protective of. Their story of an outsider entering their home community may be a completely different story than the version Meaghan shared. Elia made his classroom a place where reading is cool—for everyone—and invited his students to become part of that place.

When we came together to do this project, our initial instinct was to write about stories that had already been resolved, the stories with the happy endings. It turned out that we found more meaning from sharing stories that represented the successes we had to fail through, and fight for. Having never worked together before, the three of us were able to draw meaning out of the stories without it being marred by a context that we suspect would infiltrate a relationship between colleagues from the same school. Stories were taken as they were presented and reflections were genuinely directed at the storyteller, and not their context. Collaborative inquiry through narrative allowed us to story our teaching lives, share those stories, reflect and then engage in re-storying, re-sharing, and re-reflecting. We freely gave of ourselves and also were given permission to freely take from one another-as colleagues, then friends.

When Meaghan and Elia wrote their initial stories, both of them noted the value of participating in a genuine discussion of events that, to an outsider, may seem germane. Yet, the stories are transformative and indicative of our future choices and direction. As an education professor, the project was also valuable for Doug as it gave him a window into the worlds of two in-service teachers. The stories, reflections, and re-reflections allowed him forge a connection with Elia and Meaghan that was based on his own teaching experiences, but also educational research and teaching practice at the university.

The process also provided many immediate and long-term benefits to our teaching practice. First, we instantly created a pedagogical bond where we could very quickly engage with each other on a variety of in-school topics, without judgment, and seek feedback for personal and professional growth. Four years later, we are still in contact, still continuously storying, sharing, and reflecting as we grow in our practice. Both of us have transitioned into different grade levels and roles within our schools, which further provides us with constant conversation about teaching and learning. A consequence of this 
experience would be that we are not direct colleagues, and we work in different school boards, so there are times that we might not have the same teaching or administrative procedures, which then diminishes our ability to assist each other with the same expediency we would if we were direct colleagues. Nevertheless, this process is easily transferable to those that we come in direct contact with daily, providing new opportunities for reflection.

\section{Collaborative Inquiry Through Narrative as Reflective Practice}

In developing a collaborative team working in different school districts as well as different grade levels, we have been able to support, encourage, and advise each other despite only meeting recently through graduate school. Narratives have been an essential conduit for us to be cooperative in this journey, as our reflections took on new meaning as inquirers, graduate students, and even as asynchronous community builders. Thus, the more that we reflected, the more we became a community of reflective practitioners. Connelly and Clandinin (1990) explain this idea of community and collaboration in narrative inquiry, as something that is not practiced nearly enough in education. We immediately noticed this gap as we began to reflect on our past through the process of storytelling and re-storying. As such, our process evolved into an authentic and genuine means of sharing, allowing for a heightened level of mutual problem solving.

As graduate students who were also full-time teachers in schools, the process for Meaghan and Elia provided immediate and long-term benefits. First, we instantly created a pedagogical bond where we could very quickly engage with each other on a variety of in-school topics, whereby we knew it would be a safe space to seek feedback for personal and professional growth. This translated seamlessly into long-term benefits, since four years later, we are still in contact, continuously storying, sharing, and reflecting as we grow our practice.

Through sharing possible solutions to classroom problems, not only did we become more confident in what reflection could do for our practice, but our students also began to reap the rewards of our pedagogical reflections. Johnson and Golombek (2002) best summarize this effect on students when they explain that, "...when teachers reflect on, describe, and analyze the factors contributing to a classroom dilemma, they confront their emotions, their moral beliefs, and the consequences of their teaching practices on the students they teach" (p. 4).

At the core of our inquiry are a variety of insights on what has worked well for us as colleagues wanting to improve practice and solve problems in the classroom. Our process has directly influenced the relationship we have with our students as well as the collegiality we've developed with our peers in our school. As we begin to spread our new learning and discoveries, reflective practice becomes ever more relevant and engaging. It is now difficult for us to say that reflective practice cannot and will not permeate itself through the educational instances in which we operate, and even further, how "...our efforts [will be] powerfully motivated by the potential of reflective practice [in creating] effective teaching" (Jay \& Johnson, 2002, p. 85). 
Collaboration and community building between teachers and professors in education can also create many positive results for teacher education practice. Doug's interaction with two in-service teachers helped him to stay grounded with the field, learning and growing along with Meaghan and Elia. As a result of this research, he has been further convinced of the efficacy not only of reflective practice for emergent teachers, but also of the importance of building communities of reflective practice. Although Doug has been using a narrative inquiry process with his students that encourages them to engage in reflective practice (Hennig et al., 2020), the results of this research have allowed for a renewed focus on community, interaction, and the creation of safe spaces for sharing, feedback, and growth.

\section{Future Possibilities}

The work that we have done in becoming collaborative, reflective practitioners is by no means complete. Sharing experiences and reflecting together on them is an ongoing event in education; one that not only improves practice for teacher and student, but also enables teachers to deeply be in contact with their peers for pedagogical support. Moving forward, we will share our learning with colleagues. Perhaps those teachers and support staff that are already highly reflective could find quick and expedient ways to improve their practice. Starting where we are allows us to further explore the nuances, benefits, and challenges of a professional learning community in our own spaces.

\section{Note}

1. We are intentionally NOT using the term narrative inquiry for our work. Although we certainly drew from that methodology (among others), we do not feel that our work truly fits the narrative inquiry paradigm. Hence, our cobbled together term of collaborative inquiry through narrative.

\section{References}

Boyd, D., Grossman, P., Lankford, H., Loeb, S., \& Wyckoff, J. (2008). Who leaves? Teacher attrition and student achievement. National Bureau of Economic Research, 1-38

Clandinin, D. J., \& Connelly, F. M. (2000). Narrative inquiry: Experience and story in qualitative research. Jossey-Bass.

Clandinin, D. J., \& Huber, J. (2002). Narrative inquiry: Toward understanding life's artistry. Curriculum Inquiry, 32(2), 161-169.

Clandinin, D. J., Pushor, D., \& Orr, A. M. (2007). Navigating sites for narrative inquiry. Journal of Teacher Education, 58(1), 21-35. https://doi:10.1177/0022487106296218

Connelly, F. M., \& Clandinin, D. J. (1990). Stories of experience and narrative inquiry.

Educational Researcher, 19(5), 2-14.

Dewey, J. (1938). Experience and education. Collier Books. 
Dewey, J. (1964). John Dewey: Selected writings. The Modern Library.

Ellis, J. (2005). Places and identity for children in classrooms and schools. Journal of the Canadian Association for Curriculum Studies, 3(2), 55-73.

Estola, E. (2003). Hope as work: Student teachers constructing their narrative identities. Scandinavian Journal of Educational Research, 47(2), 181-203.

Farrell, T. S. (2016). Anniversary article: The practices of encouraging TESOL teachers to engage in reflective practice: An appraisal of recent research contributions. Language Teaching Research, 20(2), $223-247$.

Gleddie, D. L., \& Schaefer, L. (2014). Autobiographical educative narratives of movement and physical education: The beginning of a journey. Revue phénEPS/PHEnex Journal, 6(3), 1-14.

Greene, M. (1995). Releasing the imagination: Essays on education, the arts and social change. Jossey-Bass.

Hennig, L., Schaefer, L., \& Gleddie, D.L. (2020). In(di)visable: Inquiring into being 'othered' as a means to teach social justice in PHETE. Physical Education and Sport Pedagogy.

https://doi:10.1080/17408989.2020.1789573

Jay, J. K., \& Johnson, K. L. (2002). Capturing complexity: A typology of reflective practice for teacher education. Teaching and Teacher Education, 18(1), 73-85.

Johnson, K. E., \& Golombek, P. R. (2002). Teachers' narrative inquiry as professional development. Cambridge University Press.

Larrivee, B. (2000). Transforming teaching practice: Becoming the critically reflective teacher.

Reflective Practice, 1(3), 293-307.

Parker, M., Patton, K., \& Tannehill, D. (2012). Mapping the landscape of communities of practice as professional development in Irish physical education. Irish Educational Studies, 31(3), 311-327.

https://doi.org/10.1080/03323315.2012.710067

Patton, K., Parker, M., \& Pratt, K. (2013). Meaningful learning in professional development: Teaching without telling. Journal of Teaching in Physical Education, 32, 441-459.

Rodgers, C. (2002). Defining reflection: Another look at John Dewey and reflective thinking. Teachers College Record, 104(4), 842-866.

Schaefer, L., \& Clandinin, J. (2011). Stories of sustaining: A narrative inquiry into the experiences of two beginning teachers. LEARNing Landscapes, 4(2), 275-295.

Silbergleid, M. (1998). Parent/ teacher communication.

http://commons.lib.niu.edu/bitstream/handle/10843/17062/Silbergleid,\%20Mindy\%2023010\%20 Kinder.pdf? sequence $=1$ 




Elia Gindin has worked for Foundations for the Future Charter Academy in Calgary for over 13 years teaching both seventh and eighth grade Language Arts, Social Studies, and various option classes including Debate and Philosophy, Drama, and Film Studies. He received his Undergraduate Degree, with distinction in History, from Mount Royal University and his Bachelor of Education degree (Masters in Teaching Program) from the University of Calgary. Most recently, Elia is a MEd graduate from the University of Alberta and since, has been enamoured with reflective practice and attempts to indoctrinate others whenever possible.



Meaghan van Steenbergen considers herself a lifelong learner and a regular reflective practitioner. She is a teacher and an Assistant Principal with the Calgary Catholic School District, as well as a BEd and MEd graduate of the University of Alberta. Experienced in a variety of Canadian classrooms, she has worked for both rural and urban boards in K-9 classrooms.

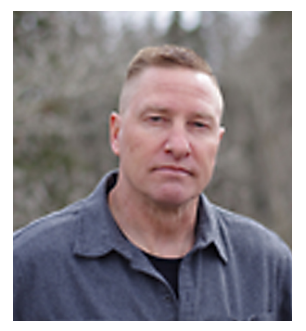

Douglas L. Gleddie is a Professor in the Faculty of Education at the University of Alberta. He teaches physical and health education curriculum and pedagogy to undergraduate students. He also works with graduate students and teaches graduate courses in physical and health education, reflective practice, physical literacy, and research methods. Douglas' research foci include: narratives of physical education; school sport; physical literacy praxis; meaningful physical education and; physical education teacher education. He is also currently the Associate Dean of Graduate Studies for the Faculty of Education. 